Comparative Philosophy Volume 4, No. 2 (2013): 82-117

Open Access / ISSN 2151-6014

www.comparativephilosophy.org

\title{
PALAEO-PHILOSOPHY: ARCHAIC IDEAS ABOUT SPACE AND TIME
}

\author{
PAUL S. MACDONALD
}

\begin{abstract}
This paper argues that efforts to understand historically remote patterns of thought are driven away from their original meaning if the investigation focuses on reconstruction of concepts, instead of cognitive 'complexes'. My paper draws on research by Jan Assmann, Jean-Jacques Glassner, Keimpe Algra, Alex Purves, Nicholas Wyatt, and others on the cultures of Ancient Greece, Israel, Egypt, Mesopotamia, and Etruria through comparative analyses of the semantic fields of spatial and temporal terms, and how these terms are shaped by their relation to the sphere of the sacred. It shows that there are three super-ordinate timeframes - the cyclical, the linear and the static-each of which is composed of lower-order cycles (days, lunar months, and seasons). These timeframes reflect their cultures' ideas about the nature, scope and power of the gods, and structure the common point-of-view about the present, the past and eternity. There are also super-ordinate spatial frames which reflect their cultures' ideas about the heavens and which structure both the sacred precinct and the profane field of action and exchange. Close analysis of texts that use words such as eternity, forever, past, present, and future, for example, do not reveal that there is anything like a general abstract concept of time in virtue of which some thing or event can be said to be in time or to have its own time. Archaic patterns of thought do not differ from our "modern" patterns in having different concepts, but in not having anything like concepts at all.
\end{abstract}

Keywords: Palaeo-philosophy, linear time, cyclical time, absolute space, relative space, Ancient Near East, Ancient Egypt, Old Testament, Homeric Greek.

This paper argues that efforts to understand historically remote patterns of thought are driven away from their original meaning if the investigation focuses on reconstruction of concepts. It is simply not appropriate to be looking for an archaic concept of space or time when considering the earliest documents which attest to their writers' (and others') belief about the genesis, structure, and extent of the world. Not only does the historian often have great difficulties in identifying and explaining relevant concepts across vast stretches of time, it may be misleading to look for anything like a concept

MACDONALD, PAUL S.: Senior Lecturer in Philosophy, Murdoch University, Australia. Email: pmcdonld@ murdoch.edu.au 
at all. The basic meaning of 'concept' is an idea that can be applied to many 'objects', an idea that is universal across a type, and not particular to an instance or token; it is abstract in its intension, i.e. it signifies an object-class in virtue of common features; and general in its extension, i.e. it can pick out numerous particulars that satisfy conditions for class-inclusion. On the Kantian view, a concept is a product of the understanding operating on empirical content supplied by the sensory faculties. Thus a single empirical concept (as opposed to an apriori, categorical concept) has a stable meaning associated with its object-class's essential properties. The Kantian concept is a unity of rule that determines all that is manifold in sensory intuition of objects and limits it to conditions that make possible conformity to type. Archaic patterns of thought do not differ from our "modern" patterns in having different concepts, but in not having anything like concepts at all. The author has published an extensive investigation of the important differences between "concept" and "complex" in an earlier paper (2005); the main findings there are provisional hypotheses in this paper.

Individual scholarly studies have been devoted to time in the Old Testament (Barr 1962, Brin 2001, Brettler 2004), in Homer and Hesiod (Clay 2003, Purves 2004, 2010), in Ancient Egypt (Assmann 1975, Pinch 2002 Chap. 2, Zivie-Coche 2004), and in Mesopotamia (Brown 2000, Glassner 2004, Rochberg 2004, 2010 Chap. XVI). Although less common than studies of concepts of time there are some studies of archaic, pre-classical concepts of space: in Ancient Greece (Kahn 1960, Algra 1995, Couprie 2011), in Ancient Egypt (Derchain 1992, Barta 1992), and in Mesopotamia (Horowitz 1998, Sjöberg 2002); pertinent collections of primary documents have been assembled by Wyatt (2001) but usually without any analyses. However, there are no cross-cultural comparative studies of the linguistic, artistic and archeological evidence from different cultures in our historical range. ${ }^{1}$ There are also many popular books with titles something like The History of Time, but they always turn out to be concerned with the history of time measurement (calendars and clocks), and not with the historical development of the conceptual framework for time.

There is sufficient documentary evidence from an "archaic" period, predating the Greek Classical period, i.e. from 1500-500 BC, (Homer, the Pentateuch, Gilgamesh, New Kingdom Texts, Amarna Sun-hymns, the Mari Letters, etc.), which show upon close examination that their concepts in general, as well as knowledge in particular, do not map directly onto our modern, post-Kantian concepts of space and time. The available textual evidence shows that their writers were working, not with concepts, but with complexes which have four salient features: (1) that it does not arise above its elements as a concept does; it merges with the concrete objects that compose it; a fusion of the general and the particular, of the complex and its elements, a psychic amalgam; (2) that its abstracted traits are unstable and easily surrender their temporary dominance to other traits; (3) that the basic level of complex formation may be the most inclusive level at which it is possible to form a mental image which is isomorphic to an average member of the class, and thus, the most abstract level at

\footnotetext{
${ }^{1}$ We await the publication of papers from the TOPOI Institute Conference (Berlin, Feb. 2012), "Cast in Space: Images, Gaze and Place in the Ancient World."
} 
which it is possible to have a relatively concrete image; (4) that it has an overabundance of properties, an over-production of connections, and weakness in abstraction. (MacDonald 2005) The unavoidable consequence of our self-imposed restriction to the palaeo-strata of documents is that we can make no use of explicitly philosophical investigations on space and time by Plato and Aristotle. However, instead of taking this to be a privation we can take it to be a challenge to uncover the ways in which ideas about space and time came to inform the background upon which classical philosophy reflected.

\section{FRAMES OF TIME AND FRAMES OF SPACE}

There have been many studies of the history of the concepts of time, especially in cosmological theories over the ages, at least since the appearance of Mircea Eliade's Cosmos and History (1954); less so for the history of concepts of space. The most common, even presumptive, point-of-view is that, from the ancient to the modern period, there have been two dominant frames (or schemes) whereby time was conceived: linear, a forward, straight sequence of steps or stages, if not towards a certain goal, then at least away from its origin; and cyclical, a pattern of moments or stages which, at some definite interval, repeats itself. It's hard to find any scholarly, serious account which does not presume these two alternatives and then classifies different cultures in various epochs in one or the other. A close look at the documentary evidence from the period under consideration here does not support this mutually exclusive choice. Such an investigation calls into question the very meaning of linear and cyclical and shows that there are other strange and little-known timeframes. And the same can be said for concepts of space which (when they are discussed at all) are usually classified as either absolute or relative; again, as we will see, a misleading and vacuous opposition for documents from 1500-500 BC.

In The Mind of Egypt Jan Assmann states that, "generally speaking, the distinction between circle and arrow, cyclical and linear time, renewal and memory may be regarded as central element in the construction of cultural time. In the form of the notion of the two eternities, Egyptian thinking displayed an equally fundamental duality." (Assmann 2002, 18) The Egyptians distinguished between cyclical and noncyclical time, calling the former neheh and the latter djet. "Neheh or cyclical time is the never-ending recurrence of the same; it is generated by the movement of the heavenly bodies and hence determined by the sun. This kind of time is associated with the concept of 'becoming', represented in the Egyptian script by the image of the scarab, the central symbol of salvation in Egyptian thought, which itself pivoted not on the idea of Being but on that of Becoming. Cycles come and go, and what takes shape in the individual cycles disappears again in the hope of renewed becoming." The other kind of time, djet, is associated with the concept of stability, of remaining, lasting, being permanent; its sign is that of the earth, its symbols are stone and mummy, its god Osiris, who guards the realm of the dead. Djet is a scared dimension of everness, where that which has become - which has ripened to its final from and is to that extent - perfect - is preserved in immutable permanence. Hence djet is not a 
linear concept of time, but rather the suspension of time. In Egyptian thinking, the opposite of the line was represented not by a circle but by the idea of a space. Djet is not linear and diachronic, nor does it consist of an ongoing succession of time points, nor is it organized into future and past. In short, it is not the locus of history. Djet is time at a standstill. Only in neheh does time move. (Assmann 2002, 19)

Assmann has already stated that there are two broad concepts or frames of time in the ancient world: cyclical and linear. In various ancient cultures time is indeed conceived as cyclical, marked by daily, seasonal and annual cycles, similar phases succeeded by similar phases. But here Assmann says that in ancient Egypt there is another notion or frame of time: as well as neheh, the cycles of days and seasons, there is also djet, the suspension of time or time at a standstill. Egyptian culture remained largely unchanged for 3000 years; the distant past would have surrounded everyone, especially near temples and monuments. Assmannn says that in ancient Egypt the "opposite of a line is not a circle but a blank, an empty space". But it's not immediately clear what "opposite" means here: the opposite of empty is full, the opposite of high is low, and so forth; but how is a circle the opposite of a line?
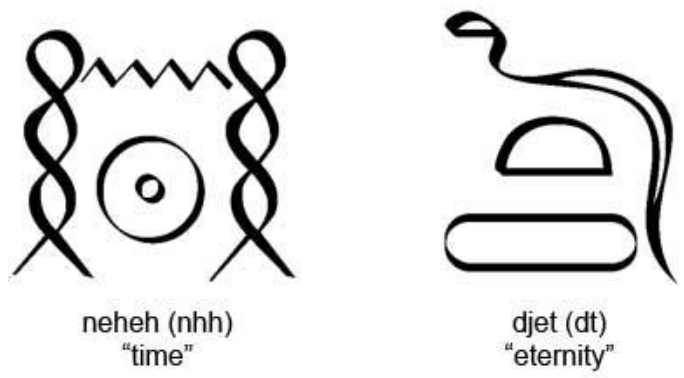

Further, how does the djet symbol, which means static or suspended time, become associated with a blank space when it shows a snake over a half-disc? The glyph for horizon (akhet) is a symbol of the sun rising over two peaks. The glyph for neheh is a zigzag line over a wheel, flanked by two braided cords. Of course, anyone, anywhere, can observe the cycle of day and night, phases of the moon, changing of the seasons, irrespective of whatever they take to be the frame of time itself. Such obvious cycles fall under, or are comprised within, linear time as well as static or suspended time; such cycles could fall under larger, macro-cycles. Some later Greek cosmologies postulated these as incredibly long, many-thousand-year cycles, from its initial start to its crashing downfall, and then resuming again in the same sequence. So this requires a higher-order concept of cycle, itself composed of ordinary, mundane cycles. But even these three time-frames might not be enough - are there others?

Christiane Zivie-Coche expresses a similar interpretation of Egyptian texts that speak of time:

It is obvious that questions occurred to people aware of life and death, of cyclical and linear time, and of the laws of nature, even if the latter were not yet on the level of 
physics .... In the strict sense of the term ... we cannot speak of Egyptian philosophy. We undoubtedly find no pure inquiry in the sense of a manifestation of a mind reflecting on a topic. But that does not mean that the concept did not exist. When the Egyptians evoked 'that which exists and does not exist', that is, being and nothingness or non-being, did they not arrive at an abstract concept free of any mythological element? Perhaps we should give up on the implicit idea, which still underlies most of our discourse that the only concepts are those that we ourselves expound. Lexicography and conceptualization have perhaps been confused. Because we can find no single, unequivocal term for 'time' in the Egyptian vocabulary, are we to conclude that there was no concept of time? [These questions] are both highly concrete and pure mind game. When we make them an object of reflection, they remain a stumbling block. $(2004,42-43)$

Turning our attention further east to the Holy Land, the Biblical concept of time in the Old Testament shows some interesting contrasts, as Marc Brettler points out.

It is difficult to talk about time as an abstraction since second-order thinking was a late arrival during the Biblical period. Thus, it is not surprising that there is no extended philosophical reflection on time and its nature. Ecclesiastes offers some thoughts and suggests periodicity of events, and perhaps even a notion of cyclical time. ... Cyclical time, however, should not be contrasted with teleological eschatological time. There is no 'end of time' according to the Bible. There are, however, various depictions of the idealized future, and these are typically based on depictions of the distant past. A cycle or, at the very least, a circle is created, through which the past and future meet. This suggests that at least for some Biblical traditions, the notions of cyclical and teleological time are not as mutually contradictory as we might have thought. (Brettler in Rosen 2004, 124)

Nicholas Wyatt informs us that, in the Ancient Near East, there are "three classes of vocabulary" with regard to spatial organization; these also serve to indicate the underlying time scheme: (1) the human ${ }^{2}$ or religious, with reference to one's own body; (2) the cosmological or solar with reference to celestial bodies, especially the sun; and (3) the topographic economic with reference to geographical measurements or local landmarks. The four cardinal points in all Ancient Near Eastern cultures of this period capture their cultures' view of the past and the future, as follows.

East: turning one's face toward the rising sun (Latin oriens); Hebrew and Ugaritic qedem (or qadm) means face, east, past; we face the past, it is in front of us.

West: the opposite of East; Hebrew 'ahar (=ahru) means back, west, and future; the future lies behind us, unseen, unknown, and unknowable. Awareness of the future causes anxiety and fear, and perhaps encourages the invention of means to predict and control it.

\footnotetext{
${ }^{2}$ Wyatt chooses to call this the "homuncular" axis, an unfortunate and misleading term; "homunculus" means "little human", a term used to describe the view that within the human mind there must be a further, deeper executive agent which makes the decisions; in the alchemical tradition a "homunculus" was a miniature human created by occult natural techniques; in any case, it is not what Wyatt means by an orientation in space centered on the embodied human being.
} 
South: facing East, South is to one's right; this corresponds with the bilaterality of brain hemisphere activity; "the right side is associated with security, well-being, and morally 'right'."

North: facing East, North is to one's left; "it represents sinister dangerous things and functions, including where the gods dwell."

The exception to this systematic arrangement of cardinal points vis-à-vis the past and future is the Ancient Egyptian view, where the principal direction is South, towards the source of the Nile River, so that everything is turned through $90^{\circ}$ : South is past, face, in-front-of; North is back, behind, future; West is to one's right; and East is to one's left. (Wyatt 2001, 35-41; tables, 42-50)

From these comparative linguistic investigations, Wyatt observes that: "On the moral-spatial axis, proximity to the self as 'centre' implies [sacred] reality, commonly expressed as holiness. This term works particularly well in English, because it contains the unifying principle of the self as one. But of course it translates a variety of ancient terms whose meaning was often separation or dedication. Temples, homes for the gods modelled on human houses, are places of 'reality' and therefore sacredness. Distance from the self means a progressive approach to the 'end of the world', where reality breaks down. Paradoxically, however, these polarities are often related in cultic activity, which may in some circumstances appear to be the process of reconciliation of contradictions and opposites, though in others it is precisely the maintenance of differences in the face of tendencies to the dissolution of categories." (Wyatt 2001, 39) According to the archaic view of space, what stretches beyond the known space established by divine activity is not best described as terra incognita, but rather as the breakdown or dissolution of reality as such. Beyond one's own land, or at least beyond anyone's known land, is not a real unknown space, but an unreal space.

As we've seen in the groups of words indicating the four cardinal directions, one pair (usually East and West) are also commonly used to indicate the past and future. "On the temporal axis, the remote past is where mythic events 'happened'," Wyatt tells us,

"providing patterns for present belief and behaviour. Rituals reactualize (re-present) the mythic realities now. Mythic time is said to be 'the eternal present' because it determines the present. Insofar as it can be tapped into through ritual and experience, we may even say that religion is perceived as having the capacity to reverse the flow of time, to annul its destructive potential. But it also provides patterns for interpreting and indeed shaping the unknown future, which can be determined, influenced or discerned through appropriate ritual and technical procedures. $(2001,39)$

As we will see, the capacity of religious ritual to reverse time's flow distinguishes it from the secular, or at least non-ritual, character of time's flow as irreversible.

In Concepts of Space in Greek Thought Keimpe Algra insists that an informed, cautious understanding of the concepts of space in the ancient Greek world has to 
overcome and move past the polarized theoretical positions which only appeared in the modern period. Algra says that,

If we ignore the difference between subjective, idealist theories of space on one hand and objective, realist theories of space on the other, one can concentrate on the different functions a concept of space fulfils within a physical theory, there are roughly three main kinds of spatial concepts. Over long periods from antiquity to the modern era, different systems have invested physical space with one of the following three functions: (a) a kind of prime stuff, (b) a framework of relative locations, or (c) a container, a space in which things are and through which they can move. The first kind of space is present in theories which tend to focus on the extension of physical things, without regarding this extension as separate or separable. According to ordinary ways of speaking and thinking, one says that a particular thing "occupies so-and-so much room" and mean nothing more than that it has a certain size. Descartes thought that extension was the principal property of body, the ultimate defining feature of substance, and thus identified extension, matter and space. This position runs into difficulties when it tries to explain local motion. Since space as extension is the constitutive element of a body and not separable from it, space is unable to play an explanatory role in the motion of physical objects. (Algra 1995, 15)

Algra says that it was for this reason that "Descartes was forced to maintain, apart from, so to speak, his metaphysical concept of space and the connected concept of what he called internal place, a concept of external place which ... defined the place or location of an individual thing in terms of (the surface of) its immediate surroundings." (See esp. Casey 1998, 137-79)

Algra makes two observations on this classification of fundamental concepts of space: first, in ordinary speech the first and third kind may well be used one for the other since they both identify space with extension; it may be irrelevant whether we think of extension as being separable or inseparable from a particular body. Algra's second comment is that all three concepts are, in one way or another, rooted in our common, ordinary experience, and hence do not embrace or endorse modern concepts of space from the mid-19th century onwards which develop ideas of non-Euclidean space, especially Einstein's General Theory of Relativity. It is inaccurate and misleading for any modern scholar to propose to read back into some ancient theory of space anything like these contemporary theories of space. (ibid) With regard to the distinction between space and place, "there seems to exist a kind of inarticulate consensus according to which 'space' is a more general term than 'place'. We may observe that 'place' is rather used in a relational setting ... whereas 'space' rather refers to an underlying frame of reference or to the sum total of all places, though ... the rules are not without exceptions." For the sake of convenience in discussing various ancient theories of space and place, Algra proposes "to adjust our descriptions of the most common philosophical and everyday usage, and to use 'place' exclusively in a relational setting (place as the place of something) and use 'space' exclusively as referring to a larger underlying extension or frame of reference, or receptacle, which constitutes the sum total of all places." He issues a caution to translators - that they should not think there is a one-to-one correspondence between the Greek term chöra 
and 'space' or between topos and 'place'. With this in mind one may classify the concepts of place into these three kinds: (a) the (material) extension of a physical body, (b) the relative location of a physical body, or (c) the extension, as part of an absolute, occupied by a physical body. Algra concludes his general overview with this summary: "Just as we saw that the threefold classification of space concepts could be reduced to two main kinds: space as extension or volume on the one hand, and space as a system of relations on the other, so too the concepts of place may be reduced to two kinds: place as an extension (whether separate or not) or place as a relative location." (Algra 1995, 19-20)

In the vast, sprawling wealth of the inimitable Dictionnaire des Mythologies, Phillipe Derchain's landmark article on Egyptian cosmology stands out. Derchain informs us that "cosmogonic thought is basic to Egyptian religion, following a general conception of a universe whose creation must be constantly begun again every time a cycle is repeated - whether it is the cycle of day and night, of the month, of the flooding of the Nile, or of a reign. Each new beginning is the equivalent of the 'first time', according to a very frequently used expression, and this gives rise to the necessity to represent the first time that accounts for all those that follow." (1992, 215) The problem of cosmogony presupposes the problem of the world before creation. Most of the sources assume that in the beginning there was a kind of chaos, a dark, frozen, and formless ocean which has always been there. It is not regarded as a void but as "a material mass containing the potential for all of the creation that would follow, a mass which can be defined only negatively, as the time in which 'there still did not exist ...'." (1992, 215-16) It's clear from some texts that Egyptian scholars grappled with the "insoluble problem of spatial or temporal infinity". However, historical inscriptions use expressions, such as "until the limits of time" or "up to the orbit of the sun" or "millions and millions of years", which suggest that the abstract concept of infinity did not exist (or was not recognized). In The Book of the Dead chapter 175 (c. 1550-1295 BC) the subject is taken up in a dialogue that contrasts Atum the creator with Osiris as the symbol of renewal. "The anguish of Osiris in the face of death in this text clears the way for two solutions: the first, in which Atum promises him that his son will succeed him, eludes the idea of the end, as it imagines a succession of generations that repeat the same acts and thus insure a cyclic infinity, whose precarious nature is left obscure. The second solution goes more directly to the heart of the problem: as a creator who is identical with the primal matter $^{3}$ that he has organized, Atum will return to this matter, bringing Osiris with him and Osiris, uniting with [Atum] in a single point, will escape the eternal return and belong definitively to the past, to a stability without duration. This return to the primordial uncreated is foreseen for a very distant future and seems to be necessarily definitive, since the powers of renewal (Osiris) or of organization (Ma'at) would be

\footnotetext{
${ }^{3}$ Infinity as primal matter is similar to one of Algra's primary time-frames, as well as to one interpretation of Anaximander's apeiron; see esp. Kahn 1960, 231-9.
} 
enclosed in it and by their conservative character would prohibit any change." (1992, 216, emphasis added)

Ancient Egyptians' ideas about the creative emergence of place, according to this time scheme, may have had their affordance their experience of the surrounding world. "The end of the world is inspired by the spectacle of the islands of the Nile that sometimes appear for a few years and, after they have borne aquatic birds and vegetation for some time, and sometimes even after they have been cultivated, are again washed by the river that carries them off until no trace of them remains." With a cyclic conception like this, a kind of permanent creation, coupled with the perpetual spectacle of nature destroying itself as it is created, it is not surprising that the Egyptians never lost their fear of annihilation. Even the best organized of worlds contained its reserves of chaos that could never be totally reduced; the best one could do was to keep the destructive forces within tolerable limits by fighting against them every day, every year. "The central problem in classical Egyptian cosmogony results from the difficulty of reconciling in one coherent image a physical universe in which all the great phenomena appear as an eternal new beginning regulated by invariable periodic cycles, combined with a necessarily linear vision of the fate of living beings." (1992, 216, emphasis added)

It seems that many significant Ancient Near Eastern religious 'complexes' are inspired by or correlated with specific visual signs like the temporary appearance of islands in the Nile; perceptual saliences that elicit a very specific cognitive response, which is then captured by a word or an ideogram. Also, in the same order of phenomena, there are the mounds of land which formed the center of Ancient Near Eastern cities at creation and the pillar that reaches to heaven. One is reminded as well of the astonishing hypothesis that the Mesopotamian imagery of the gods' weapons, such as lightning, explosions, and liquid fire, were inspired by unstable volcanic seepage in the high plateaus. And again, that for thousands of years the Marsh Arabs in Southern Iraq built their houses and corrals on giant reed mats which float on the watery marshes. Sumerian pictograms from the early third millennium show the same floating reed houses; habitable space emerged from the surrounding waters (the apzu). H. A. G. Frankfurt raised this strange question about Egyptian pictorial art in relation to their landscape:

why amongst several possibilities the cubic and not ... the conical form should have been chosen as a structural system it would be well to remember that Egyptian art was born in a country where for a length of 500 miles a life-giving stream and a narrow strip of fertile land are hemmed in by the ruthless parallel lines of cliffs that mark its boundaries; beyond lies the desert, beyond lies death. The Egyptian land south of Cairo does not know a circular horizon; orientations run at right angles, and distinctive directions are not only clear-cut and final - they are pregnant with meaning. (Frankfurt 1978, 27)

After the production of the Earth and Sky through the actions of the creator god, "the organization of space is possible, the organization of time follows later, after the last generation of the Ennead becomes operative." This is followed by the 
construction of a systematic dualism, both cosmological and political, which permits an organization of the world on the basis of the association of opposites.

The opposites include light and darkness, order and disorder, male and female, life and death, being and nothingness, and Upper and Lower Egypt ... to the extent of constituting pairs such as black and red, and infinite duration and extra-temporal eternity ... as well as an opposition between the world and the beyond, which leads to the opposition between matter and spirit, and between reality and myth, whose indispensable connection the Egyptians always felt deeply. It might be possible to describe in this way the mental schema by which the Egyptians built their cosmogonies. The schema has been described here as independent of the particular forms of the cosmogonic myth that are related to local conditions and to the individual fantasies of those who invented them. $(1992,218)$

\section{TIME, ETERNITY AND THE MOMENT}

We now turn our attention to textual evidence for patterns of archaic ideas about time and what they show about an overall time frame, cyclical, linear or otherwise. According to Jan Assmann in The Search for God in Ancient Egypt (2001), "the meaning of this disjunctive concept of time and its two components cannot be translated by any pair of words in Western languages. The Egyptian terms in no way correspond to our "time" and "eternity"; this distinction derived from Greek ontology (eternity as the punctually concentrated presence of being, which unfolds in time as the process of becoming) was not only foreign to Egyptian thought, but even contrary to it. Neheh and djet both have properties of our "time," as well as of our "eternity," and as a practical matter, either can sometimes be translated as "time" and sometimes as "eternity." The terms refer to the totality (as such, sacred and in a sense transcendent and thus "eternal") of cosmic time. To clarify this concept of time and its religious implications or semantic range, we must heed an important distinction. We are so accustomed to the notion of infinity that we think of "totality" as finite and bounded. The Egyptians, however, viewed "totality" as the opposite of finite and bounded. To them, the boundaries of totality were not contrasted with the unbounded, but with the "whole," with "plenitude." $(2001,74)$

In an earlier monograph on the subject, Zeit und Ewigkeit in alten Agypten (1975), Assmann referred to an important Late Period magical-religious text:

"The ritual, which guarantees continuity, is conceived as the union of the two antagonistic gods Re and Osiris. This 'union' of the God of the sun and the God of death; the God of perpetual motion and change, and the God of peace and unalterable duration, is not a 'syncretic' fusion, but a periodic process, which is celebrated ritually. Continuity implies time in the form of periodicity: a periodic crisis as the periodic overcoming of the manifestation of continuity. The night is such a crisis, but also the change of rulers, and death as a transition from one form of being to another. Each change implies a crisis that is corrected by the ritual union of the two antagonistic principles - Re and Osiris on the cosmic level, $b a$ (soul) and the corpse on the anthropological level.... The combination of neheh as the principle of perpetual and periodic regenerative time and djet as the principle that permanence persists in constant self-sameness and this results in a 
conception of continuity at a high level of abstraction." This conjunctive concept then embraces two otherwise opposed ideas of time. "One cannot place this continuity on a level with the concepts that are treated here under 'time' and 'eternity'. Continuity implies time, but with the further benefit of addition, a decisive time. Continuity is the identity of a periodically renewed time advancing and regressing with itself and - at the most general level, possibly achieved through the combination of neheh and djet - you have for this system the 'world' as a whole, that is, the 'order of things'. With the idea of periodic renewal the idea of a periodic crisis is necessarily given. It is here, and not in the eschatological conception of an absolute horizon of time and being, that is the place for the topic of the 'inverted world' and the evocation of catastrophe. (1975, 25-26)

The Egyptian concepts of time and space emerge from an examination of their cosmic myths, according to Zivie-Coche (2004, 45; see also Pinch 2002 Chapter 2). Many images and phrases from their creation accounts describe Nun the primordial ocean, for which she offers this minimalist definition: Nun was an unformed and dark mass, for light had not yet been created, in which divine beings or dead people who had achieved divine status could circulate. But how can this mass be defined, since we have no knowledge of it, since it is absolute nothingness or non-being. It is that which pre-existed, the uncreated, the unformed, the undifferentiated, the atemporal, to which was opposed, after its creation, the cosmos ruled by order. Nun was an inert principle who contained in himself all the possibilities, all the virtualities of being, some of which would be activated at creation. He harbored raw matter which certain texts call benenet, mother-substance, whose nature the Egyptians did not clarify. Nun was what was before anything came into existence, defined in negative terms. Nun is also characterized by permanence - he subsists after the creation of the cosmos, He was pushed back to the limits of the universe, where he existed above and below the earth. The sun sank back into Nun at night and rose from it in the morning. This "diffuse, constant presence is constitutive of Egyptian cosmological thought and its system of logic.... It seems that the Egyptians were unable to conceive the existence of the cosmos as a negation of Nun."

Zivie-Coche speculates on the significance of this: "I think that this apprehension of the cosmos, which is based on the rejection of exclusion and on the consubstantial permanence of what we call contraries, is one of the most complex and subtle approaches to the incommensurable reality of being." $(2004,47)$ If one were to inquire as to the reasons that led them to account for the origins of the world in this fashion, "the Egyptian concept was not born from pure speculation of the mind, but rather from observations of natural, geographical, and physical phenomena that were transposed onto the level of metaphysics and mythology". (ibid) This speculative formulation, coupled with her earlier remark that their concept of time was "both highly concrete and pure mind game", clearly points us in the direction of what, at the outset, we called a cognitive complex. Unlike an abstract, general concept a cognitive complex does not arise above its elements; it merges with the concrete objects that compose it; it is a fusion of the general and the particular, of the complex and its elements, a psychic amalgam. 
After the first appearance of the creator god "a mound emerged where he could stand; none of the texts tell us how the first mound emerged. Matter was already in Nun, waiting to be coagulated to a point where the dry contrasted with unformed matter. But this was not matter of the earth, of this world which still did not exist." $(2004,51)$ Hence, Nun always existed - Nun who is not being, is also not nothing. It thus seems he was accorded neither beginning nor ending. From this confused massiness the creator god emerged and took form in order to give birth to the world this is called the "First Occasion. Several important religious sites are actually called "the place of the beginning of time". Unlike the Biblical Genesis the moment of creation, the commencement of all things, is not dated; the origin of the world is not computable - and this has something to do with the Egyptian conception of time. The 'First Occasion' marked an absolute rupture between the before, when there was something but nothing happened, and the after, when the process of creation was definitely set in motion. But once there was 'an occasion', it had to reproduce itself, and it did this an incalculable number of times. The First Occasion was followed by an infinity of others, of which the Egyptians often said they occurred 'like the First Occasion'. Here we encounter a fundamental given in a concept of time that was cyclical. It was made up of periods that renewed themselves, first and foremost, the daily rising of the sun. There were also the annual return of the inundation and the beginning of the year and, on a no longer natural but historical level, the succession of the reigns of the pharaohs." (2004, 52, emphasis added) Zivie-Coche surmises that "It was these repetitions of the First Occasion that assured the continuity of the world in its periodicity .... It seems that the primordial act of the creator god had encountered no obstacle, but that each of its repetitions, which were inevitable in nonlinear time, was subject to the risk of failure, of catastrophe, and that human beings, once they had come into existence, were in some way constrained to participate in the functioning of the cosmos." $(2004,53)$

Thus, in contrast to the Biblical Genesis, "the cosmogonic texts do not offer the carefully fixed calendar of a process each step of which was duly recorded and which ended in the creation of man and his companion as a unique couple, the pause sign at the end of a week of incessant activity." Note here that each "step" is a day and a day is a stage in a sequence which itself has a character or meaning, like words in a sentence. "For the Egyptian creator god, time does not seem to have been a factor, though all creatures and all things did not appear simultaneously. We can speak of a succession, but is was not measured or divided according to the reckoning of time, which certain texts otherwise tell us was itself created and set in motion by the creator god." $(2004,59)$ So, temporal succession was not a factor in the divine creation of the world, nor is it a factor in the Egyptian perception of time as a series of sequential moments. A major hymn to the goddess Neith, recited at Esna, states that: "she made the moment, she created the hours, she made the years, she created the months, she gave birth to the season of inundation, to winter, to summer." Nun, however, was beyond the limits of time; in this world life and death divided or separated out. The gods were masters of human lifetime; but ordinary human life was otherwise marked with ruptures, "through which that which continued to subsist outside time insinuated 
itself. Thus, Egyptians considered sleep and dreams as parentheses in life, during which the disordered forces of Nun could surge forth." $(2004,60)$

Zivie-Coche seems to backtrack somewhat - or step away from the direction of her own argument - when she opens the next section, stating that there are two ways to imagine time: linear and cyclical. Linear time, she says, is apparent (or at work) in human lifetime, marked by a beginning and an ending, despite Egyptians' concerted efforts to conceive bodily death as the transition to another life. The time allocated to each human was fixed from the start by the gods. "But for the Egyptians, the linear character of time scarcely seems to have exceeded the domain of individual existence. Linearity did not apply to cosmic time, or even to historical time. The First Occasion never served as an absolute beginning or start-point of time, not because time had no beginning, but because the beginning was destined to be repeated indefinitely." In contrast, in the historical dimension, the principal factor was the perpetuation of the same, the continuity of kingship from pharaoh to pharaoh.

This cyclical functioning played a fundamental role in cosmic time, of which historical time was only an application. ... The march of time was ruled by the obligatory passage from day to night and from night to day, from light to shadow, the return of the inundation, the beginning of the new year. Each of these passages was a source of danger, a threat of dysfunction, and an irruption of disorder. $(2004,66)$

Let us widen the scope of this investigation. According to G. W. Trompf's analyses of a wide variety of ancient texts ${ }^{4}(1979,2-3)$, the major time paradigms in the ancient world are as follows:

(1) The cyclical view: the belief that history or historical phenomena pass through a fixed sequence of at least three stages, returning to what is understood to be an original point of departure, and beginning the cycle again.

(2) The alteration (or fluctuation) view: there is a movement in history wherein one set of general conditions is regularly succeeded by another, which then in turn gives way to the first.

(3) The reciprocal view: common types of events are followed by consequences in such a way as to exemplify a general pattern in history; departures from some mean are continually rectified; good and bad actions recurrently evoke their appropriate desert.

(4) The reenactment view: a given action (usually taken to be of great significance) has been repeated later in the actions of others. The imitation version of this view acknowledges recurrence because a person has consciously copied the actions or habits of another.

\footnotetext{
${ }^{4}$ In an exhaustive study of Polybius' Histories (c. 170 CE) Tromp discerns in Polybius' theory of the cycles of polities (anacyclōsis politeiōn) a zig-zag pattern which is structurally parallel (or at least similar) to Glassner's interpretation of the Sumerian king-lists. (1979, 5-6) The anacyclossis was the natural course or order in which constitutions change, are transformed, and return again to their original stage (Polybius Histories VI.ix.10) Since Polybius' work falls outside the historical scope of this paper it is not discussed any further.
} 
(5) Conceptions of restoration, renovation, and renaissance entail the belief that a set of (approved) general conditions constitutes a revival of a former set which had been considered defunct or dying.

(6) The typical view: certain kinds of social change are typical and are to be described by a recognized terminology; the recurrences of these changes do not necessarily belong within a cyclical, alternating or reciprocal process.

(7) The human-centered view proceeding from a belief in the uniformity of human nature; it holds that because human nature does not change, the same sort of events can recur at any time.

(8) Other minor cases of recurrence include the isolation of any two specific events which bear a very striking similarity and the preoccupation with parallelism, that is, with resemblances, both general and precise, between separate sets of historical phenomena.

Documents from the ancient cultures of Mesopotamia exhibit time concepts intermediate between continuous duration and cyclical alteration; plotting the shape of the terms in which these concepts are expressed shows striking similarities with Trompf's zigzag model. In the Mesopotamian Chronicles, according to their editor Jacques Glassner (2004), "time was the basic component of history. It was a powerful force governing all things that could be propitious for some activities but dangerous for others; it was even sometimes considered as a demiurge." Past time was called in Akkadian pānānu or mahru, 'formerly', that is, 'before', while the future was called warkātu, 'that which is behind'. The Akkadians and the Sumerians "advanced backward toward the future while looking toward the past, following the example of Gilgamesh, who, in the Akkadian epic, advanced toward the unknown to which he turned his back: 'When he had gone seven double-leagues, dense was the darkness; it would not let him see what lay behind him'." Mesopotamia did not know linear time, Glassner declares;

Two concepts of time developed simultaneously, insisting on the ideas of duration and of cycle. The first was time that flowed on, conceivable and manageable by a calendar, divisible into equal measurable units of time that were all cyclical - years, months, and days - and referred to by the Akkadian words dāru and duru, from the same Semitic root $d w r$ which means 'to turn, to move in a circle', and denotes a time that proceeds from a point of departure but has no future limit. Mesopotamian historians were concerned primarily to locate events in this first concept of time, which is also that of chronology. $(2004,7)$

Several Sumerian and Akkadian expressions refer to time as duration and promise eternal life or eternal kingship, where 'eternal' means as long as the life or the gods' kingship gods endure. One of these expressions (Akkadian ana ümī sati) means 'until the day of going out' or 'until the going out of days', which expresses the idea of the past approaching the present to move off into the future. The second concept of time was the cyclical, expressed by Sumerian bala and Akkadian palü. "The latter term, denoting periods separated from one another, can also mean 'change'. This mode of time can be imagined by reference to the cycles of the seasons and the succession of 
the generations. Reckoning generations, that is, connection with ancestors, counts for more than the distance that separates them." $(2004,8)$ However, if the world was not understood using the category of progress, on the other hand it was not thought to be in a static condition.

The category 'change' existed, and in the juridical vocabulary of Akkadian the expression ana dūr u pala 'for continuity and change', meant the totality of future time. Furthermore, 'rotation' did not mean simple repetition, because each repetition generated new content. The Mesopotamians did not reread ad infinitum the pages of the same book, nor were they passive spectators of the same performance repeated ad infinitum. The relationship between the past, the present, and the future was founded not on strict repetition but on similarity. (ibid)

In short, the study of the past fell under the rubric of analogy, history being a cyclical process, hence made up of recurrent events and peopled with avatars. The Mesopotamians thought that the universe was permeated by a complex network of homologies, which tended to bring into relation matters that otherwise seemed remote from each other.

Humanity, nature, and the cosmos existed in reciprocal relationships, each adjusting, communicating, and responding to one another. This network of sympathies was countered by groups of incompatibilities that enclosed species in their own specificity, and "evil forces" that destroyed symmetry existed. History, with its discontinuous time fragmented into numerous segments variously charged qualitatively, indefinitely repeatable yet fully dissociated one from the other, could not transcend these general laws, which divination illumined with ever-sharper focus. $(2004,17)$

When Glassner examined several significant king lists he observed that the successive periods during which one city held kingship are called by the same word bala. "This term indicated, rather than a linear, quantitative, or homogenous time flow, one that was seen as a structural and qualitative relationship between two points. Rather than to a duration of fixed length it referred to a span within that duration, the specific length of which could vary from a few days to several years." Time was measured by the number and the duration of the successive dynasties. In sum, its dating system was a reflection of the relationship among cycles of rule. It has become conventional to translate bala as 'dynasty, but 'dynasty' denotes a succession of rulers of the same bloodline. The word 'cycle' would be preferable, allowing a distinction between family cycle and local cycle. The same local cycle may embrace several family cycles, and conversely, family cycle and local cycle may be the same. Thus, "the unfolding of history could be represented as a series of cycles, each selfcontained. These cycles succeeded one another according to a definite order and lasted for their allotted time, until the cities that were home to them were conquered, destroyed or abandoned." (2004, 65, emphasis added) Reversion to a normal state of affairs required a process of foundation, essential for bringing about a return to order after a transition. And this entailed a sequence of foundations and their attendant 
narratives; "foundation", Glassner tells us, "means marking off a space, distinguished form the rest of the world by being given a location and a name." (ibid) Here the succession of foundations, each instituting an original creative act, recalls the Egyptian concept of the repeated First Occasion.

In the Chronicle of the Single Monarchy one can discern a theoretical construct: the linear presentation succinctly lays out its content by listing events and cycles at the same time, and thus offers the reader a synoptic view of information reduced to pertinent facts arranged according to a principle of familial order, the cycles succeeding one another in linear fashion like human generations. "The document was thus consciously and deliberately constructed, but as an inevitable result of its reduction to writing the cyclical passage of time is no longer clearly visible. Moreover, it arranged in succession what could actually have occurred simultaneously, for an effect of writing down was to create by simplification a superficial order that was more a reflection of the physical arrangement of the text than of intellectual speculation." Glassner proposes that this reading of the chronicle can be represented by what he calls a "sinusoidal diagram".

This layout has the advantage of highlighting the moments of transition and of presenting significant episodes as successive and ordered points in a linear sequence. The procedure adopted by ancient scribes, of linear deployment, simplified the author's thinking to the point of making it incomprehensible, by reducing it to a one-dimensional form, although the presence of biographical notices, however short, added a two-dimensional character. The sinusoidal diagram allows restoration of the cyclical motion that constraints of writing had obliterated. $(2004,67-8)$

Following a complete reconstruction of the sequence of dynastic foundations Glassner concludes: "A sinusoidal reading, then, has the merit of demonstrating one aspect of the chronicler's thought that would otherwise be invisible: the affirmation of the continuity of monarchy in Mesopotamia and its discontinuity elsewhere, where in any case, if the truth be told, it had no place. Once the formula had been found, it was merely a question of applying it." However, the linear dimension, in the course of time, appears to have superseded and replaced the cyclical perception. "The Chronicle of the Single Monarchy was an official canon reflecting the views of its time. The indisputable quality of the work makes it a source of the first importance for the study of historical writing and political thought at the end of the third millennium." (2004, 70)

There is a striking parallel to the sinusoidal shape of the succession of Sumerian royal foundations in the attempt by Babylonian astronomers to describe observable variations in celestial phenomena. According to Christopher Walker, the simplest technique is what is called "a linear zigzag function", where a quantity increases or decreases by a constant amount (d) in successive intervals, reflecting off some fixed maximum (M) and minimum (m). The earliest known examples of linear zigzag functions are found in Tablet XIV of the astrological series Enuma Anu Enlil which was composed toward the end of the second millennium. "Here we find two 
functions, one of which described the amount of time the moon is visible at night over the course of a month, and another which describes the variation of the increment of the first function over the course of a year. Both functions give values in time-degrees ... reflecting an early introduction of this unit [=4 mins], and both use proper sexagesimal place-value notation to express these values." Walker concludes his analysis with these words: "These simple functions reflect the extreme age of the arithmetical techniques underlying linear zigzag functions. They also comprise the earliest example we possess of the separation of a complex phenomenon into components describable by simple arithmetic functions, each with its own independent variable." (Walker 1996, 55-56)

We can further demonstrate the power and extent of this time-frame by returning briefly to our consideration of Egyptian ideas about time: neheh as continuous time, djet as eternity, suspended time. The Egyptians were obsessed with the afterlife, the land of the dead, and many of their great texts deal with it at considerable length. The Pyramid Texts of the Old Kingdom (c.2350-2180 BCE), the Coffin Texts of the Middle Kingdom (c.1987-1640 BCE), and the various Books of the Underworld (the best known of which is the Book of the Dead) in the New Kingdom (c.1540-1075 BCE). One of the lesser known of the Coffin Texts, The Book of Two Ways, opens with a one-of-a-kind painting or vignette, which depicts a long sinuous path through the land of light in the upper register, and a comparable, nearly matching path through the land of darkness in the lower register. This vast scene is a spatial representation of the temporal sequence of a dead soul's passage through the afterlife. It should be noted as well that the hieroglyph for neheh was a zigzag line over a wheel, flanked by two braided cords, a sinuous line which doubles back on itself.

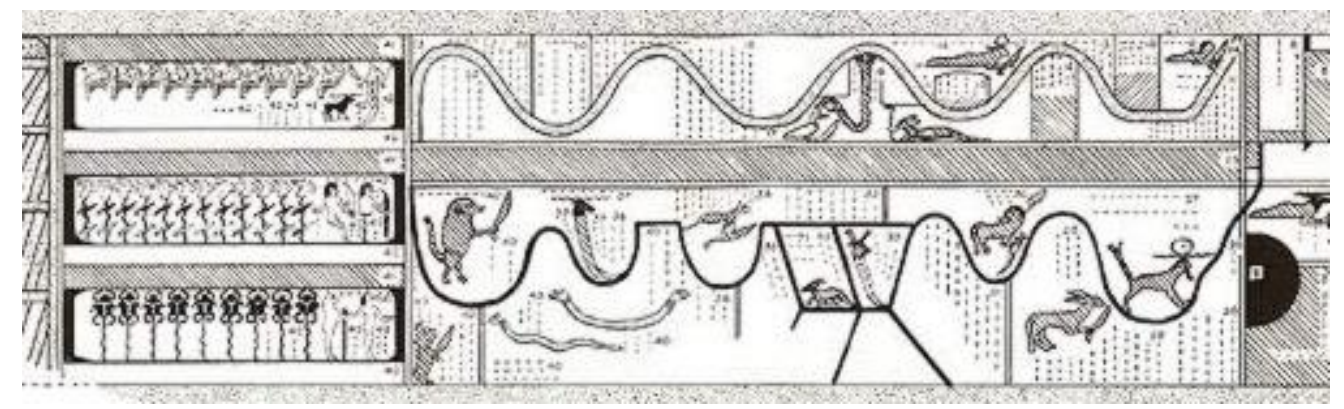

The Book of Two Ways was copied on the inside bottoms of nobles' coffins, probably so that the deceased would have this guide at their feet when walking in the underworld. Leonard Lesko says that "the book received its name because of the two zigzag paths that form a kind of map for the use of the deceased." (Lesko 1977, 2-3) The goals of the deceased were not only the famous Field of Offerings, but also the mansion or palace of Osiris, the mansion of the moon, and the solar bark. Demons who guard the flaming red gates may be the same as those from two chapters of the Book of the Dead. If the map was a guide for the deceased he would have had some trouble since there are so many errors in the texts' transcription. "Since the deceased had to know how to pass on both ways and since the ways meet at the far end of the 
map, we can assume that a circuit of the ways was intended, beginning and ending at the gates.... This circuit is associated with the voyage of solar and lunar barks through the sky (upper waterway) and underworld (land-way)." (Lesko 1977, 43; see also Bonacker 1950, 5-17)

With regard to the background time-frame in the Hebrew Old Testament, the most common (though sometimes tacit) assumption is that it is some kind of cycle, perhaps recurrent, perhaps repetitious. Perhaps the most famous text used to establish the cyclical character of time in the Bible is this often quoted chapter from the third book of Ecclesiastes. "To every thing there is a season, and a time to every purpose under the heaven." This famous passage does not mean that humans have any say in deciding the time to do anything important; every type of event has its "time" (= proper place) in the divine scheme of things. Marc Brettler declares that this chapter of Ecclesiastes, "the Preacher", is one of the strongest statements of periodicity in the Bible; although it is reflected in other earlier texts as well. Jeremiah 5:24 notes that God can be thought of as the One "who gives the rain, the early and late rain in season"; the climate in Israel is extremely predictable, the rainy season stretches from October through March, and it's rare for it to ever rain between May and Sept. The Preacher opened the book with the statement that nothing new occurs outside the cycle of historical events. (Here the word "vanity" is from vanitas which means "empty" or "void".) "Vanity of vanities, says the Preacher, vanity of vanities; all is vanity. What profit has a man of all his labour which he takes under the sun? ... The thing that has been, it is that which shall be; and that which is done is that which shall be done: and there is no new thing under the sun." (Eccles 1.2-5)

The long-standing, usually unexamined opposition between cyclical time and linear time is open to another interpretation. In Biblical scholarship since at least the mid-19th C. the end-point or telos of linear time has been called the eschaton, a Greek word that means "the farthest extent in space, the final element of time, and the last piece of money." This modern convention is based on the Greek LXX for the Hebrew, often translated as the "end of days", and in the King James Version as the "last days". Brettler observes that the use of eschaton "prejudges the situation, suggesting that there is an end of time. Thus native terms for what may be more neutrally called the ideal future must be studied to see the extent to which this period is conceived of as an end and the extent to which earlier time periods are viewed as inextricably leading up to it." (ibid 120) However, the Hebrew terminology used for describing the ideal future never refers to the "end of time"; this is also true for the time in the Dead Sea Scrolls. It's more common to see a phrase which means "the day of God" or "that day", often in prophetic books. None of the relevant contexts suggests that the time marked out by the phrase is the end, since "those days" or "coming days" initiate a long time period, admittedly in the future, but not as the end of time or when days come to an end. The most familiar phrase in English translation is the "end of days", especially in apocalyptic texts; but this is an incorrect translation from the Hebrew which dates to the composition of the Greek in the LXX. It would be better translated as "the days to come"; where "this is a prophecy that is meant to 
transpire in the future, but there is nothing to suggest that this is 'the end of time'." (ibid 121)

In sum, Brettler concludes, "those who depict Biblical time as linear, with the 'end of time' as a goal or telos, are misreading the text. Prophetic literature presents a set of traditions that describe an ideal future that in some distinctive ways ... will be fundamentally different. But this is depicted as a long period, in which life is otherwise normal. Furthermore, it is typically unclear if this period is to last forever." (ibid 122) In many cases, references to "the days to come" is often phrased not as a final era, but a return to an old era, the renewal, for example, of God's covenant with Israel. "This notion, quite literally, brings us full circle, creating a certain irony. There is no end of time ... but the texts that describe the future often do so in terms of the past, and thus view events as cyclical, or at least as recurring." (ibid 123) The extraordinary irony here is that the very opposition between linear, goal-directed time and cyclic, recurrent time is spurious and collapses under the weight of textual evidence; "for some Biblical traditions, the notions of cyclical and teleological time are not as mutually contradictory as we might have thought."

The Hebrew word yōm is the central concept used in the OT to express various ideas pertaining to time, Gershon Brin informs us; it appears more than 2300 times, the fifth most frequently used word in the OT. The authors created a wide spectrum of other terms and phrases, but their main task was the refinement of meaning of this term. ${ }^{5}$ There are three main approaches to indicate time: (1) phrases designate a date according to time following a given act; (2) phrases indicate a time equivalent to a given act; (3) phrases indicate a date prior to a given act. The phrase "now at that time" sometimes serves to unite events in one span, but often it's clear that such "an integration into a single complex is impossible." It is an empty rhetorical phrase or formula, "a combination of words had already detached from the simple meaning of the words and simply serves as a means of connection by the authors, redactors, and editors between different portions of a work." (Brin 2001, 2-3) The Hebrew word dur is used to designate a span of years rather than a point in time. By using the expression "in the days of so-and-so" the Biblical authors found "a simple way to define periods; this signified the beginning of the crystallization of an overall vision of sporadic events that are thereby organized into a perceptual whole." In sum, Biblical authors were persistent in perfecting the methods they developed so that one explicit pole alone (starting or ending) was sufficient. The height of abstraction was reached in formulae of uninterrupted duration, whether by means of a formula or by not mentioning the concluding pole." (Brin 2001, 8)

Roughly contemporary with the historical setting of the first five books of the OT are the composition and background of Hesiod's Theogony and Works and Days (c.720-700). Hesiod described the structure and order of time from two different points-of-view. In the Theogony, an epic poem which describes the evolution of the cosmos, Alex Purves tells us, "Hesiod presents time as a linear construct, plotted

\footnotetext{
${ }^{5}$ See also Barr, Biblical Words for Time, SCM Press, 1962, 99-100; John Wilch, Time and Event: An Exegetical Study of the Use of 'eth in the OT. E. J. Brill, 1969.
} 
upon a genealogical, diachronic history that runs from the birth of the gods to the present order of the universe. In the Works and Days, a didactic poem that instructs the reader on the correct way to manage a farm and a household, the poet focuses on the circular motion, as it is relayed through the cyclical pattern of seasons, months, and days." (Purves in Rosen 2004, 147) These two time schemes are prescribed by their marked difference in genre: epic time elapses according to a different logic than the didactic, just as historical time flows at a different rate than the seasonal. In both works, Alex Purves looks to uncover the ways in which "Hesiod contrived to hold time in abeyance through the domestic or agrarian metaphor of preserving goods in jars beneath the earth .... [This leads to] a spatial understanding of time in the Theogony, in which different temporal registers, such as the future and the past, are 'stored' underground." (ibid 148)

Large portions of the Works and Days are concerned with teaching or training the farmer to recognize the correct times at which to carry out specific jobs. "The Works and Days can thus be regarded as an elaborate set of instructions on how to seize the present moment, for each event ... has its own precise point of timeliness within the ordered scheme of the Hesiodic calendar." However, the injunction to grasp the "ever-fleeting immediacy" of the right time is countered by a more general, higherorder necessity, namely the need to live not entirely in the present, but one step ahead of it. Hesiod repeatedly urges his readers to anticipate and provide for the future. The pressing need, which the author enjoins on his readers, is "to ration out the present to spread it thin over the less productive seasons of the year. The poet recommends doing this by storing up grain and wine in large jars ... which - along with a wellstocked granary - should only be broken open at certain specified times." (Purves 2004, 152; see also Clay 2003, 31-48) By way of this simple, ordinary analogue to storage jars, Hesiod develops the scheme of dividing time itself into the separate categories of past, present, and future. The jar's empty capacity, its "space" serves as a "holding bay" for the present, or perhaps for the "present-as-yet-unspent", a kind of container for time.

Hesiod tells us the story of Pandora given a large jar (pithos) by Zeus (not a box, as it's usually said) during an age when humans did not know evil or diseases or hard toil. But then Pandora removed the jar's lid and released all the "hard sorrows" which scattered amongst mankind, leaving only hope, stuck inside the jar, trapped there when Pandora put the lid back on. "Pandora opens up a new region of time as she opens up the space of the jar", Purves observes.

For in the gap ... the race of iron is created, forever caught in the cycle of mortal birth and death which hovers in the brief period between the opening and shutting of the jar. It is not only disease and sorrow that Pandora allows to escape by lifting the lid of her pithos, but time as well, resigning humans to a fate trapped between the hedges of the past and future, in a present which is to be spent and re-spent in a continuous cycle." (Purves 2004, 153) 
The parallel with the Genesis story of Adam and Eve is obvious: the time between an idyllic period when there is no disease or hard labor, birth or death, and the period when humans must work and suffer, subject to birth and death; this transition is marked by the introduction of evil things through breaching the command to not eat of the tree's fruit.

In contrast to the Works and Days, Hesiod's other great poem the Theogony deals not with the limited range of human time, but with the expansive time of divine mythology, the cosmogony or stage-wise birth and progress of the gods. (Purves 2004, 155-60; Clay 2003, 13-30) "The central problem of the Theogony", Purves informs us, "lies in reconciling this diachronic genealogy of the gods with the synchronic, eternal present ushered in by Zeus, who alone of the immortals manages successfully to put a halt to the progression of time. For Zeus not only overcomes the older gods of the past, but he also, by swallowing both offspring and wife, transforms his own body into a container that holds the future indefinitely in reserve." One question which the Theogony poses is how to make sense of the relation between the divine time scheme where Zeus rules always from end to end and the human time scheme of seasons and years, births and deaths. "In the immortal setting of Hesiod's Theogony, the past is always unexhausted. Since the gods cannot pass out of existence, so too can the past never be brought to full completion. It can only be removed from the present by being contained or put on hold for some moment in the future."

The other principal image for time in Hesiod is Tartaros, the underworld, encircled by an impenetrable wall of bronze, three layers of darkness, and the backward-flowing streams of the river ocean. In Hesiod's scheme the underworld is a place without progress or development through time. "Instead it is bound by the laws of stasis and repetition, where things remain unchanged. In some cases, as with the exchange of Night and Day across its threshold, that repetition validates the cyclical, natural patterns of time in the world above. But for those trapped within the walls of Tartaros, there is explicitly no exit, no 'place' for time to go." In terms of the plot line, the underworld "serves as the site to which all dead ends lead - within which the machinery of various unfulfilled (but ever-present) story-lines winds down and is abandoned." By making the underworld "a kind of vast, makeshift jar that ... will never be opened, Zeus definitively separates off the categories of the past and future from his own all-encompassing present." Thus, Tartaros functions as "an archive which binds a previous but ever-present generation of gods in an eternal state of stasis, as if 'frozen' in an earlier age. More importantly, and also paradoxically, Tartaros functions as a kind of 'oubliette', a secret underground dungeon, which substitutes for the human process of forgetting." (Purves 2004, 163-5)

\footnotetext{
${ }^{6}$ Umberto Eco recently commented (This is not the End of the Book, Vintage Books, 2012) that he thinks that many of our contemporary inventions are the manifestations of very ancient dreams. In Book VI of the Aeneid Aeneas visits the underworld to search out the spirits of the dead and not-yetborn. "It's as if Virgil had created a virtual world rather like the entrails of a vast computer crowded with silent avatars."
} 
Hesiod's divine-human time-scheme has echoes in archaic Etruscan imagery. In her paper "The Conception of Time among the Etruscans", Marjatta Nielsen uses the text of Censorinus' de die natali (238 AD) to explore the Etruscans' strange, anomalous view of time-periods. According to Censorinus, the Etruscans believed that the earth, their nation, and individuals had been given a certain time by the gods. The earth would last for twelve millennia (chiliades); the Etruscans had been given one of them, divided into ten saecula, not necessarily 100 years each. One saeculum corresponds to the lifespan of the longest living person born in the first year of the new saeculum. "This must have required quite a bit of anagraphic administration. On the other hand, the gods helped in keeping the record, giving a very clear sign when it was over and a new one begins." Reconstruction by scholars shows that Etruscan history, according to their own scheme, began in $968 \mathrm{BC}$, and ended at the year 0 (i.e. Christ's birth, but by coincidence). The beginning and ending correspond very well with the historical and archaeological evidence for Etruscan culture. (And thus this 3rd C. AD document records an archaic view of their own time scheme.) The doctrine of saecula as part of Etruscan religious discipline "also implied a cyclical repetitive conception of time. It belonged to the priests' duties to keep records of natural phenomena, the means for predicting the future; gods expressed their will by sending signs, analogous to those on similar occasions." $(1999,36)$ The cyclical concept of time also appears in their art: among thousands of figural scenes, repetitions of events happening at different times were deliberately brought together to convey the idea of the interdependence between the past, the present, and the future; every event is conditioned by the past, and will have consequences in the future." $(1999,38)$ Such a cyclical conception could also be expressed within one and the same scene, not only by depicting moments of a story, sequences of past happenings, according to the normal technique of pictorial narration, but also by including allusions to the future, by introducing figures of soothsayers, prophets, dreamers or the like. Some scholars, Nielsen reports, have connected elaborate figurative scenes on Etruscan mirrors to the cyclical concept of time, in the sense that the mirror image may have been thought to belong to the realm of the shades and spirits of the dead.

\section{SPACE, PLACE AND VOID}

The most exhaustive treatment of the entire corpus of maps in the Ancient Near East is Wayne Horowitz's magisterial Mesopotamian Cosmic Geography (1998) where he records, transcribes, and analyzes every extant fragment of cuneiform text relating to the earth and heavens. One study will suffice: two tablets provide information on the levels of the universe; the first is a religious explanatory text in Neo-Assyrian from Assur, the second a late astrological tablet. Although both are from the first millennium, they may date back to the Kassite period (c. 1600-1155 BCE) The colophon on the first describes the tablet as "a secret of the Great Gods". The three heavens are composed of different types of stone, and there was an open space between each floor, just as there is an open space between the earth's surface and the 
lower heavens. It may be assumed that each stone floor was visible from below and served as a roof for the region above. This finds support in a parallel from Exodus where the floor of heaven was apparently built of blue brick: "the seventy elders of Israel rose up and they saw the God of Israel, and beneath his feet was the likeness of sapphire brick just like the heavens for clarity". (Ex 24:9-10; cf. Ezek. 1:26-28) Thus, the blue floor of heaven in Exodus when seen from below may be identified with the blue background colour of the sky on clear days and the darker blue of clear night skies." $(1998,9)$

The Upper Heavens are assigned to Anu, a well known image which occurs in numerous texts. The first tablet states that it is made of stone whose appearance is red with white and black patches. The Middle Heavens are made of another stone whose appearance is like lapis-lazuli. "The texts suggest that the bottom surface of the Middle Heavens was visible from the earth's surface." Where the Upper Heavens were the abode of the Iggigi gods, the Middle Heavens contain the cella or shrine of the god Bel. The text states that the god made a lamp shine in the cella, perhaps a lamp made of electrum. The Lower Heavens, where the stars belong, are made of jasper, a type of chalcedony, a hard glassy, often translucent stone. Another text describes grey jasper that has the appearance of an overcast sky and another jasper that has the appearance of a clear sky. "On clear sunny days, the blue sky often appears to be tinged yellow by the sun .... On cloudy days the lowest portion of heaven appears to be coloured grey by clouds, while on sunny days, the lowest portion of heaven seems to be clear, open sky." $(1998,10)$ The text also describes the three earths (or three levels of earth): the Upper Earth is inhabited by human spirits, the Middle Earth by Ea (=Enki), and the Lower Earth by the 600 Anunnaki (young gods). Each lives on the dannatu (surface) of their earth and since these levels correspond with the levels of heaven it can also mean "floor". Human spirits are not the ghosts of the dead, but living humans, dwelling just under the floor of the Lower Heaven. The Middle Earth belongs to Ea/Enki, who ordinarily occupies the Apsu (cosmic ocean); in Enuma Elish, Ea occupies the Apsu when Anu and Enlil take possession of the heavens and Esharra. The Lower Earth is the underworld where Bel imprisoned the 600 Anunnaki; an equivalent name for the underworld is erset la târi, "earth of no return", which implies the Anunnaki cannot hope to escape their punishment. Here Horowitz points out the parallel with Hesiod's Theogony where Zeus imprisons his enemies in Tartarus. $(1998,17)$

The Ancient Near Eastern account of three heavens and three earths, coupled with the creation story of Marduk's battle with Tiamat is embedded in the Biblical account of creation, though in an abbreviated form, as Rochberg argues. "And God said let there be a firmament in the midst of the waters, and let it separate the waters from the waters. And God made the firmament and separated the waters which were under the firmament from the waters which were above the firmament. And it was so. And God called the firmament heaven." (Gen. 1.6-8) The meaning and location of these "waters" above and below the firmament raised questions for Biblical interpreters from the early Church Fathers onwards. Were the waters above the firmament some sort of physical matter or an immaterial realm? Two features of ANE cosmogony are 
at work here: that the world came to be from an original watery state and as the result of the separation of heaven and earth. In one Mesopotamian myth, it was the goddess Nammu ("mother") from whom emanated the cosmic regions above and below and these became the two principal elements for all further creation. In the Old Testament one sees Leviathan and Rahab, fantastic monsters associated with the sea; in Job 26:12 it says, "By his power he quelled the sea | By his cunning he smote Rahab. | By his wind he bagged the sea, | His hand pierced the fleeing serpent." Isaiah 51:9-10 does not relate the cosmic battle to creation: "was it not you who dried up the sea, the waters of the great deep; that made the depths of the sea a way for the redeemed to pass over?" But Psalms 74:14-17 clearly relates this event to cosmogony: "You are the one who smashed the sea with your might $\mid$ cracked the heads of the Tannin in the waters. | You are the one who crushed the heads of Leviathan, | left him as food ... | You are the one who broke open springs and streams | you are the one who dried up the mighty rivers." And then in parallel with Marduk in the Enuma Elish: "To you belongs the day, yours too the night, | You are the one who established the light of the sun. |You are the one who fixed all the boundaries of the world, | summer and winter - it was you who fashioned them." Rochberg comments that "unlike in Ugaritic myth the sea became a mere representation of an obsolete god in the Biblical reworking, demoted to the rank of a demon rebelling against the almighty." (Rochberg $2010 \mathrm{p}$. 343) In Enuma Elish the sea monster, slain by Marduk, was split into two parts: one part was made as a roof, the other as a floor; the heavens contain the waters of Tiamat, guarded and held by a tightly stretched skin. "Obviously, a rational account for water above in the heavens was desirable ... it falls as rain. The idea of a cosmic feature to function as a barrier between the heavenly waters above and the earth below may also be identified in literary texts where the celestial realm of the planetary deities is sometimes denoted by the term [for] 'base of heaven' ... translated as the "firmament'." (Rochberg 2010, 344; see also Lambert 1975, 55; Sjöberg 2002, 237)

The Enuma Elish also tells us that "Marduk constructed a reed frame on the face of the waters. He created dirt and poured it out by the reed frame. In order to settle the gods in the dwelling He created mankind." Amid the primeval sea, Gwendolyn Leick explains, "the first city Eridu, and the great temple of Babylon are 'made' - or rather, conceived through an act of divine thought that sparks of the process of actual creation. Just like the marsh dwellers of southern Iraq who still build their huts on floating islands of reeds, the god spreads mud upon a reed-frame to fashion a platform. From this primordial, rather flimsy basis, the cities and their temples take their beginnings." And thus, "the Mesopotamian Eden is not a garden but a city, formed from a piece of dry land surrounded by waters. The first building is a temple. Then mankind is created to render service to god and temple." The situation of the primeval city of Eridu is unique. "It is one of the most southerly sites, at the very edge of the alluvial river plain and close to the marshes: the transitional zone between sea and land, with its shifting watercourses, islands, and deep reed thickets." The city commanded its own ecosystem "since it was built upon a hillock within a depression about 20 feet below the level of the surrounding land, which allowed the subterranean 
waters to collect together. This swampy place can still become a sizable lake in the months of high water." The actual geographical setting of Eridu accords very well with the Mesopotamian notion of the cosmos: "the earth was a solid disc-like expanse within a huge body of water. Below the earth was the $a b z u$, while above the earth the sky formed a more or less impermeable vault holding back the upper body of water, which at certain places and times fell as rain through the holes in the sky's ceiling. Eridu was the centre of the cult for the god or goddess of sweet water." (Leick 2001, 2-3)

Regarding perceptions of space in general, Glassner tells us, "if the Mesopotamians generally condensed their geography into sequences of toponyms ... they also felt the necessity of drawing up maps, admittedly another means of enumeration. Two examples are noteworthy: (1) the map of the empire of Sargon of Akkade is presented as a long list of places enhanced with indications of distances, each province being defined on it by a plain line joining extreme points. ... (2) The Babylonian map of the world (below) (Horowitz 1988, 1998) is presented as a drawing and appears to be a response to a search for a model based on the qualities of circular form and on the striving for symmetry that this allows. Its layout serves to define a rational order that reduces the increasing complexity of the real world. This map, which represents a striking mastery over the forms of the universe, is not an image of the objective world but illustrates a myth or an epic." (Glassner 2004, 28-29 note 17) Babylon is shown in the centre (the rectangle in the top half of the circle), and Assyria, Elam, and other places are also named. The central area is ringed by a circular waterway labelled Salt-Sea. The outer rim of the sea is surrounded by what were probably originally eight regions, each indicated by a triangle, labelled Region or Island, and marked with the distance in between. The adjacent cuneiform text describes these regions, and it seems that strange and mythical beasts as well as great heroes lived there, although the text is far from complete.

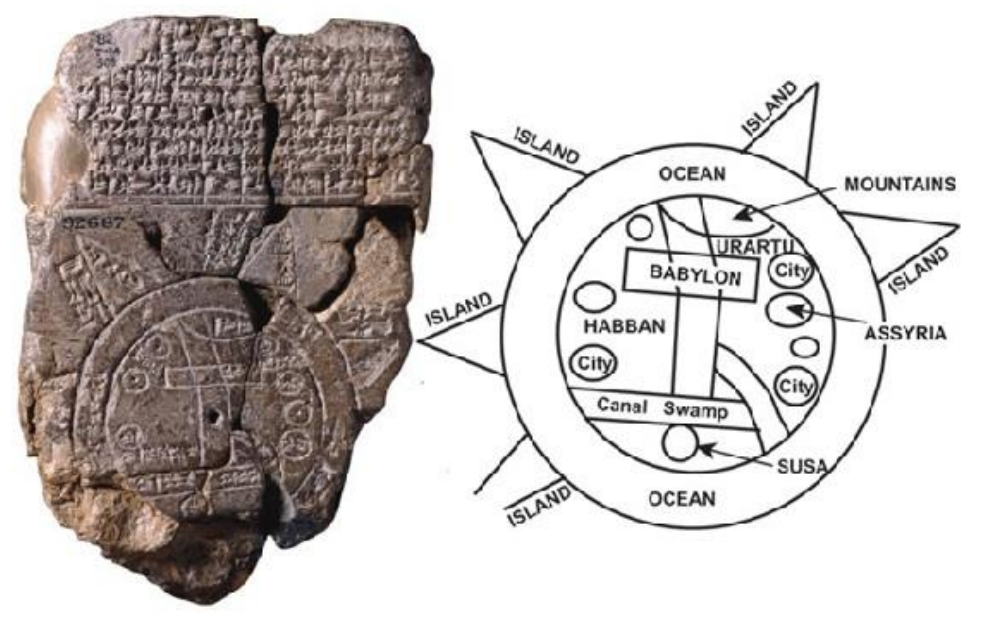


In the Old Testament the physical sense of māqôm can refer to the following: spatial distance, a dwelling place, living space, lack of space, the absence of a clean surface on a table, the absence of a space for a mount to pass through, a locality or city, the appointed place to stay, one's place at a table, ground given up in a battle, an area suitable for pasture and settlement, one's own home. (TDOT vol. 8, 532-42) The word $m \bar{a} q \hat{o} m$ can also evoke notions of order or organization where it occurs most often in cosmic contexts: wisdom understands that each and every thing has its 'place'. Since order is in many ways unfathomable to humans, the term can also function as an expression of mystery, of that which is inaccessible to human beings in both the cosmic and the spiritual realm. The Preacher is probably referring to a person's social station or official position when he issues a warning (Eccles 10:4); the sense of office or 'official place' is clearer in other texts (Eccles 3:16; 1Kings 20:24). In the Preacher's lament the $m \bar{a} q \hat{o} m$ 'ehād is the end fated for every person according to the senseless order of death, probably also referring to the netherworld. In more neutral usage, the term can refer without theological overtones to the land of one's birth or of certain peoples. The Preacher also binds specific ceremonies to specific places inside or outside the temple, the tent, camp or city. It is the place where an animal is sacrificed, the place where ashes are poured out.

The initial division of the cosmos in Genesis undergoes some refinement in the Psalms, which interposes a third dimension (the world or earth), perhaps owing something to each of the others, thus having both celestial and infernal characteristics. This reflects or parallels the creation of the first human, and Wyatt observes that it is common to see cosmogony connected with anthropogony. "The voice of your thunder was in the dome of heaven, | lightning lit up the world | the underworld shuddered and shook. | On sea was your pathway | and your train was on mighty waters." (Ps 77:1819) And later: "To you belong the heavens and to you the underworld. | The world and all that fills it you established. | Saphon and Sea you divided, | Tabor and Hermon delight in your name." (Ps 89:11-12) Wyatt comments that the "infill" is set within the primary binary opposition; this emphasizes its temporality. "This is not intended to denigrate it, but indicates its fragility and ephemerality, and perhaps hints at its own creativity and versatility. It seems that a stark realism lies at the back; try as we may, the entire edifice will eventually come crashing down." (Wyatt 2001, 76)

From Ugarit comes an important text about the celestial enthronement of god (similar in many respects to enthronement of a human king): "Athar the brilliant went up into the furthest parts of Saphon; he sat on the throne of valiant Baal. [But] his feet did not reach the footstool, his head did not come to its top." The Ugaritic word for "top" here is apsh, cognate with Akkadian apsû, though the sense of "ocean" is not present in this context. But the term does refer to the remotest part of the cosmos where the encircling ocean would be encountered. "We are therefore to understand this divine throne as an axis mundi, reaching vertically through the whole universe. The image of Isaiah 66:1 (from about 800 years later) provides a clear means to its understanding, where Yahweh declares: the heavens are my throne and the 'eres [underworld] is my footstool." (Wyatt 2001, 77) Another text from Isaiah provides associated imagery: "all the nations are as nothing before him; as far as he is 
concerned they are (as) utter waste." Wyatt comments that, "the poet surely evokes nonentity less in abstract, conceptual terms as in spatial terms; reality is that which is contained within the bounds of the universe, and all is bounded with water. If we wished to be perhaps a little over-bold, we might offer the following as grasping at the meaning implied: 'All the nations are as well-water before him; as far as he is concerned they are upper and lower seas.' The sense on this reading would imply that the nations, so precious to those who belong to them, are merely the raw material of creation from a divine perspective. They can be remade at any time." (Wyatt 2001, 114-15)

As we have seen, Kiempe Algra proposed that from the ancient world onward different systems have invested physical space with one of the following three functions: (a) a kind of prime stuff, (b) a framework of relative locations, or (c) a container, a space in which things are and through which they can move. We have synopsized these views under two broad space-schemes: space as a relative distribution of objects in proximate relations, and space as an absolute container in which objects have their places. (Algra 1995, 15-20) However, as we stated at the start of this investigation the unavoidable consequence of our self-imposed restriction to the palaeo-strata of documents is that we can make no use of explicitly philosophical reflections on space and time by Plato and Aristotle. Never the less, we can carefully describe the terminus ad quem towards which ancient Greek words for space, place and void developed in the classical period. The common Greek word topos has a wide semantic range in its general sense; it can refer to geographical space, the whole earth, a region or a country. It can also mean the site of a building or a room in a house. But it is also space in a loose sense, the place one holds for someone, or a space in a document, a particular place in a text or a passage in an author, even a specific rhetorical style. (LSJ 1968, 1806) The common Greek word kenon when used of things means empty and is in contrast with pleōs which means full, filled or complete. When used with respect to aspirations or ambitions, kenon signifies fruitless, destitute, or bereft; it can be used to describe a person as devoid of wit, as vain or pretentious; thus kenotic space is barely space at all, it is deficient or empty space. The word kenon has a link with topos insofar as topos can refer to an empty place in a document, or even a blank page. (LSJ 1968, 938)

The richest, most complex Greek word is chöra which, like topos, can refer to a country or a land, but with the specific sense of dwelling or occupying, as in an estate or a town, or to the country in contrast to the city. (Note the distinction between country as a specific geographical area and country as outside-the-city.) In contrast with both topos and kenon, the word chora has a social or political overtone; it is a place that's occupied, where some important thing is located; or in an extended, metaphorical sense, one's place in life, one's fate; it is the space where something is at stake. The verbal form chōreo indicates, not so much to aim at or move toward, but rather leaving one's place in order to move to a new place; it is not simply a vacation, but rather a giving-way, receding, making room for something else. (LSJ 1968, 2015) In Homer's Iliad (IL 8.491) the abstract space of choros is described as a definite space, a piece of ground that is clear of dead bodies, i.e. not filled by the dead or the 
deadly. It is the position or proper place of a person or a thing, e.g. a soldier's post (IL 23.349) Homer compares an area (choron) on Achilles' shield to a dancing floor made by Daedalus for Ariadne in Knossos (IL 18.590) Indra McEwen comments that "the measure of the dancing floor was the measure of the dance itself. The place appeared with the dance and disappeared when the dance was over. Its independent status was not even an issue. .... [Homer] does not say that the dancing floor was made first and that only then did the dance take place. ... The dancing floor seems to emerge with the dancing of the youths and maidens." (McEwen 1993, 62-3) In An Introduction to Metaphysics, Heidegger remarked that Homeric Greek had no word for 'space' as such; they experienced the spatial on the basis not of extension but of place (topos); they experienced it as chora, which signifies neither place nor space but that which is occupied by what stands there. (Heidegger 1987, 66)

The sketchy picture of Homeric ideas about space and place is paralleled in the mythical figures of the gods Hermes and Hestia (though this parallel can be treated only as an illustration and not as evidence.) In an ingenious interpretation of Ancient Greek myths about the little-studied pair of deities Hermes and Hestia, Jean-Pierre Vernant discerns the significance of their stipulated functions for an understanding of Greek ideas about spatial organization. "The Greeks who worshipped these deities never saw them as symbols of space and movement. The construction or structuring of a pantheon was ruled by a logic that is not in accordance with our criteria. Religious thought obeys its own rules of classification. It defines and classifies phenomena by distinguishing between different types of agent, by comparing and contrasting various kinds of activity. In this system space and movement are not yet interpreted in the form of abstract ideas. They remain implicit in that they are incorporated in more material and more dynamic aspects of reality." The contrast between the two gods becomes clear with respect to their practical functions.

If Hestia is apparently capable of 'centering' space while Hermes can 'mobilize' it, that is because as divine powers they are the patrons of a series of activities undoubtedly dealing with the organization of earth and space, and even constituting in terms of praxis the framework within which, for the ancient Greek, the experience of space took place -- but which never the less covers a very much wider field than that implied when we [today] talk of space and movement. (Vernant 1983, 127-32, emphasis added)

Although there is a great deal of information about Hermes, from myths, images and rituals, not much is said or shown about Hestia. Homer says nothing about her, Hesiod and Pindar only briefly mention her, but a few lines from the Homeric Hymn to Hestia do indicate the way in which the two deities were closely associated - in terms of their affinity of function in the Greek conception of space and place. The Hymn says that "the two gods in friendship dwell together in the glorious houses of men who live on the earth's surface." Hestia resides in the middle of the Mycenaean house, in the round hearth which marks the center of the human dwelling. In his own way Hermes is also associated with human habitats and, more generally, with the terrestrial sphere. "In contrast to the distant gods who dwell in an outer region, 
Hermes is a familiar god who frequents this world. Living among mortals on terms of intimacy, he introduces the divine presence into the very heart of the world of mankind." Hermes manifests himself on earth in the form of a messenger, "a traveler from afar and one who is already preparing to depart. Nothing about him is settled, stable, permanent, restricted, or definite. He represents, in space and in the human world, movement and flow, mutation and transition, contact between foreign elements." (Vernant ibid)

If Hermes and Hestia form a couple in the religious beliefs of the Greeks, "it is because the two deities belong to the same plane, their action applies to the same field of reality, and their functions are interrelated." With regard to Hestia's function her significance in Greek thought is obvious: her fate is to reign at the center of the domestic sphere, forever immobile; whereas Hermes is her complement, the swiftfooted god who rules the traveler's sphere. "To Hestia belongs the world of the interior, the enclosed, the stable, the retreat of the human group within itself; to Hermes, the outside world, opportunity, movement, interchange with others. It could be said that, by virtue of their polarity, the Hermes-Hestia couple represents the tension that is so marked in the archaic conception of space: for space requires a center, a nodal point, with a special value, from which all directions, all different in quality, may be channeled and defined; yet at the same time space appears as the medium of movement implying the possibility of transition and passage from any point to another." (Vernant ibid)

Our last set of documents comes from Etruria and although the latest extant texts date from the 1st-2nd C. BC, their antiquity attests to an earlier context in the 8th-7th C. According to Edlund-Berry's study of Etruscan ritual space (2006), any space, whether sacred or secular, is defined by its boundaries. In a landscape like Tuscany, "these spaces are most commonly defined by the natural setting, the presence of rivers and lakes, narrow valleys, caves, and groves. The terms for such spaces and boundaries are usually known from the Latin vocabulary ... but exist also in the limited Etruscan nomenclature preserved in inscriptions or referred to in Latin texts." $(2006,116)$ According to the so-called prophecy of Vegoia, the division of land and the establishment of boundaries was the result of Jupiter's (i.e. Tinia's) interaction with humans. The reason for his action was to create order and to prevent human greed for land from upsetting the established balance of ownership." Varro said that boundaries were part of Etruscan science (disciplina) since the division of the world according to the cardinal points was designed by the Etruscan priests or diviners (haruspices). Boundaries were under the protection of deities; for example, Tul and Selvans; although there is no known image of Tul, there is a statuette of Selvans from Cortona which shows him as a young man, like the companion piece of Culsans, the two-faced god similar to the Roman Janus. "Selvans is usually equated with the god of woods or wooded spaces defined by three boundaries, rather than Terminus, the abstract Roman boundary deity known from the Capitoline Hill in Rome." (2006, 117)

There are two main sources for the Etruscan view of space: the Piacenza liver model and the Roman author Martianus Capella's description of the Etruscan heavens 
in The Marriage of Mercury and Philology. The bronze liver model found near Piacenza, dated to the 1st or 2nd C. BC, is inscribed with names of deities arranged in cells or wedges of different sizes, separated by incised lines. Sixteen cells along the edge of the upper side in a continuous band around the center, which itself is divided into 24 more segments, each with an inscribed name. (van der Meer 1987) The underside of the liver model is divided into two halves by an incised line, one side labeled TIFS (=Moon) and VSILS (=Sun). What both examples illustrate, according to Edlund-Berry, is "an absolute need for defining spaces as contiguous entities, related to each other by a common border, but also separate from each other because of the very same border, and because of the deity in charge of each space. Regardless of the nature of each specific space, each gains its identity and strength by being part of a pattern, a design of molecules with infinite possibilities for expansion." Furthermore, "these contiguous spaces ... not only extended horizontally on earth or in heaven, but provided vertical links between heaven and earth, and between earth and the underworld. In heaven the orientation of the regions was guided by the spatial directions: north, south, east, and west. On earth, these celestial spaces corresponded with a variety of spaces: first, the delimited, inaugurated spaces, templum or auguraculum, from which the sky was observed; second, the temenos or enclosed space around a sanctuary, including features such as altars and temples; and third, features in nature such as mountains, rivers, lakes, and groves." $(2006,118)$

The connection between the heavens, the earth, and the underworld is further expressed by terms referring to "openings" in the earth, such as a pit dug in the earth for offerings of fruits, known as mundus. In the setting of the Etruscan landscape, such openings were reflected in natural formations such as the lakes formed by extinct volcanic carters or in caves set in the hill slopes." In parallel with the Etruscan division of space their calendar divided time. The Zagreb mummy wrapping and the so-called Capua Tile indicate segments of time in days, months, and parts of the year "suggest that the Etruscans were as meticulous in their time management as they were in establishing the order of the universe through appropriate boundaries defining different kinds of spaces." (2006 p. 119) "The hill provided a defined space for habitation, further reinforced by the city wall.... Only when viewing the steep hill from below, or by finding that a nearby hill is separated by water, does an inhabitant of an area, or a visitor, friend or foe appreciate the pattern of boundaries - vertical as well as horizontal.

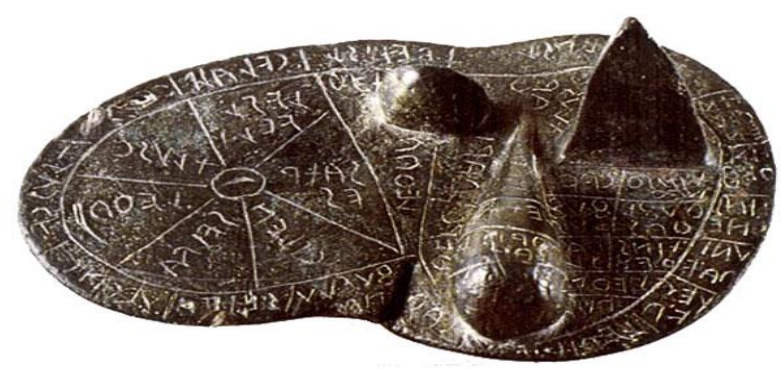


The Etruscans thought that the liver was the seat of the soul; its shape, contours and lines concealed valuable information which the trained haruspex could interpret, tracing the connections between the "little world" (the liver) and the "great world" (the heavens). The Piacenza liver model (above) was probably used as an exemplum for teaching the haruspicial techniques; it is divided into sixteen sections in the outer zone, and many more sections within the interior zones, each section inscribed with an Etruscan god or star name. (van der Meer 1987) In a recent article Natalie Stevens has made a good stab at figuring out its most likely use as an instrument to determine forecasts from observation of the heavenly bodies. She argues that the Etruscan heaven was subject to a seasonal movement of two regions per season, a clockwise and a counter-clockwise rotating movement, influenced by the positions of sunrise and sunset on the solstices and equinoxes. Temples of the god Tin (=Jupiter) are oriented to the south and those of Uni (=Juno) to the southwest. These are taken as fixed terrestrial positions; this allows reconstruction of 16 earth regions which are counterparts of the 16-part heavens. These are numbered clockwise, beginning with the region just east of north as region 1. Since Etruscan gods were supposed to dwell in different parts of the heavens, temple orientation is related to divine dwelling places in the heavens. Where the Romans knew only a four-part heaven the Etruscans divided them into 16 parts as early as the 7 th $\mathrm{C}$. BC. Haruspices used the partitions to read the will of the gods by noting, for example, the direction of lightning: eastern parts were favorable and western parts unfavorable. (Stevens 2009, 153-64)

\section{CONCLUSION}

At the start we had to contend with the presumption that there were only ever two contrastive and opposed time schemes - linear and cyclical. In the final analysis, historical, linguistic, cultural examination of different cultures in different epochs had to assign a given culture's time scheme to one or the other. Scholars such as Mircea Eliade, C. J. Whitrow, Penelope Corfield, Stephen Jay Gould, and others were content with this binary division or duality. But everything we've looked at above has challenged this presumption on two fronts: first, that there are only two options, one the opposite of the other; and second, that archaic cultures employed anything like the concept of cycle or the concept of line. Cycles are not the same as circles: a cycle is a sequence of movements, from a specifiable point to the same point according to a uniform process. An example of a cycle which is not a circle is a digital clock which displays minutes from 00 to 59 and then 00 again; whereas a circle is an already completed cycle with a definite geometrical shape. A wheel rolling over the ground lays out a line, but so does a stone dragged along the ground. A straight line spinning around a point marks out a circle as a cycle. A caterpillar tractor marks out a line by the motion of segmental tracks around two extremities, moving in equal but opposite directions.

Of course, anyone, anywhere, can observe the cycle of day and night, phases of the moon, changing of the seasons, irrespective of whatever they take to be the frame of time itself. Such obvious cycles fall under, or are comprised within, linear time as 
well as static or suspended time; such cycles could fall under larger, macro-cycles. So this requires a higher-order concept of cycle, itself composed of ordinary, mundane cycles. Thus it becomes apparent that super-ordinate time frames permit various combinations: (1) a platform carried on a set of wheels; (2) cycles within cycles; (3) cycles whose motions turn larger concentric cycles; (4) cycles whose segments are themselves cycles; or (5) cycles whose motions entrain cycles in a line. In addition to a line and a cycle we've also seen time conceived as a zigzag or sine-wave, as well as time suspended or static. Where the void permits the passage of objects in motion (as in Epicurus), so also suspended time permits the lower-order cycles of days, months, and seasons without itself cycling or lining-up. Jacob Bronowski once speculated that only cultures with wheels and wagons expressed cosmologies with spheres and circles.

The analogy of time's arrow is no more helpful or insightful than time as a cycle: an arrow is a straight length of something which traverses an extent or a distance. But extent and distance are spatial concepts - time cannot move like an arrow! An arrow is something which moves in a line with respect to a frame - it cannot establish or constitute the frame itself. Further, one does not need the concept of straight line in order to choose or make a straight arrow. Just rotate the shaft rapidly between your hands while staring at the point; if it wobbles then it's not straight. The same is true, of course, for anything that needs to be circular; one doesn't need the concept of a circle in order to make a wheel. Although one can derived the concept of a cycle from repeated observations of day and night, and the phases of the moon, one does not need the concept in order to observe these alterations. And certainly the concept of a macro-cyclical time-frame is not derived in any way from observation of lower-order cycles, no matter how many times they have been observed.

The archaic, pre-classical mentality about humans' orientation to their past and future is preserved in certain curious figures of speech (in English, anyway): "turning your back on the past", "putting the past behind us", and "facing up to what we've done". Each of these reveals that the alteration in personal point-of-view, in order for one to move forward, means that before the alteration we were already facing the past, which we now turn our back on or put behind us. As Nicholas Wyatt says, "I stand on a line going from east to west, from past to future. I am moving along this line backwards. The past recedes and every moment I experience is already a past experience." (2001, 37) (Wyatt notes that this line can be straight, crooked or cyclical.) In Egyptian paintings from all periods humans and gods are often shown in profile, but only the gods are shown full-face, humans never. What does this show about the gods' orientation to their past and future? For all the cultures we have examined, characteristic of archaic mentality as such is that one faces the past, the past is in front, and one faces away from the future, the future is behind. Perhaps this temporal orientation is reflected in the archaic inversion of the idea of historical 'progress'; according to Hesiod humankind has declined from the age of gold to the age of silver, then bronze and now iron. Hesiod (and others later) saw steady 'regress' from the most distant past to the present and on into the future. 
In the searchable database of the Electronic Text Corpus of Sumerian Literature (ETCSL) there is no single word translated by "space" and there are only about a dozen instances of any Sumerian-Akkadian word translated by "place"; in those cases it is always the site of something, a ruler, a statue, a temple, and so forth. The same is true in Egyptian where the glyph for heh is merely a "place-holder" (sic) for something. The OT word $m \bar{a} q \hat{o} m$ is similar, since it stands in or is periphrastic for land, area, seat, temple, etc. The important point is that there is no concept of space nothing like any of the three Ancient Greek concepts laid out by Kiempe Algra relative, absolute, extensive material. In the documentary evidence from the archaic period there is no indication of an outer or greater frame which things occupy or in which they have a coordinate location. The mounds which rise out of the waters are places sui generis, each itself the home or seat of a divine power.

The outer zones of an archaic world map would not be labelled terra incognita, as though there were other "lands", ones that were now unknown, but could become known. Beyond the known lands, formed from divinely endowed cities, there was terra irrealia "unreal lands"; places not already known were not real. The surrounding waters or ocean filled the area between the earth and the heavens; they occupied an intermediate stage between something stable, durable, material and something permanent, immutable in the heavens; water is halfway between earth and nothing; the remnant of the primordial matrix (apsu, nun, okeanos) from which all things emerged. Thus soil, land, stones, trees, and so forth partook equally of both the stable domain instituted by the gods and the infinitely mutable waters. An excellent indication of this view is that the Hebrew OT, Egyptian, and Mesopotamian pictures or models of the cosmos show that the heavens are continuous with the edges of the earth: a flat disc of three levels surmounted by a vault or dome which abutted its periphery (picture a glass dome over a platter). There was no empty space between the earth's edges and the pillars of heaven because there was no concept of space that could be empty. The levels of heaven were solid place-occupiers, made of translucent metal or crystal; the stars were either fiery bodies embedded in the orbs or holes through which the cosmic fire shone.

It is possible to connect the image of time as a circle or wheel with the image of space "spun out" at the world's creation. In the Mesopotamian creation story Atrahasis Nintu fashions humans out of clay, but there is no mention of a potter's wheel; whereas in one Egyptian creation account Khnum the creator god is described as a potter at his wheel shaping the world. This wheel-imagery returns in Timaeus' account of the demiurge using his mixing bowl, a circular receptacle, to shape the world; its centrifugal force spins out the shapes of things. Matter on a spinning wheel in the space of original creation corresponds to time in cycles. Further, in Egyptian and Mesopotamian accounts of creation a mound emerges from the waters, each god's domain is its home mound (i.e. its temple); the central ben-stone, like the axis of a wheel, connects the earth and the heavens, turning in cycles around the earth. This is comparable to the Homeric-Hesiodic image of Hestia as the central hearth pillar, connecting the abode of humans and that of the gods. Even the most distinctive artistic invention of the Mesopotamians, the cylinder seal, is indicative of their view 
of space: cylinder seals are the opposite of a magic lantern; where a cylinder seal rolls out to impress its images on a linear surface, a magic lantern casts its images by spinning around an inner light. Cylinder seals unroll into a linear design, which could be called a frieze; the word "frieze" is from the Latin phrygius, in the Phrygian style, but it could just as well be "freeze", a linear design which results from "freezing" a circular motion. The very idea of linear time, of time conceived as an arrow, is the result of freezing the cyclical motion of wheels within wheels, and those too inside wheels; the centre, the earth of our space and time, is almost without motion, at a standstill.

\section{ACKNOWLEDGEMENTS}

This is the place to express my thanks to two anonymous reviewers for the journal whose criticisms and suggestions prompted me to reframe some of the evidence and recast some of the main lines of argument; the present paper has benefited greatly from their advice. My thanks to the editor, as well, for helping me clarify some of my key terms and for permitting me to submit a paper of such considerable length.

\section{REFERENCES}

Algra, Kiempe (1995), Concepts of Space in Greek Thought (Leiden: E. J. Brill). Assmann, Jan (1975), Zeit und Ewigkeit in alten Agypten (Heidelberg: C. Winter).

Assmann, Jan (1995), Egyptian Solar Religion in the New Kingdom, trans by Anthony Alcock (London: Kegan Paul).

Assmann, Jan (2001), The Search for God in Ancient Egypt (Ithaca, NY: Cornell University Press).

Assmann, Jan (2002), The Mind of Egypt: History and Meaning in the Time of the Pharaohs, trans. by Andrew Jenkins (NY: Henry Holt).

Barr, James (1962), Biblical Words for Time (London: SCM Press).

Bartholomew, Craig (2009), Ecclesiastes (Baker Bible Commentary).

Barta, Winfried (1992), "Die Bedeutung der Personifikation Huh in Unterscheid den Personifikation Hah und Nun", Gottinger Miszellen, 127: 7-12.

Bonacker, William (1950), "The Egyptian Book of Two Ways", Imago Mundi, 7: 517.

Brettler, Marc (2004), "Cyclical and Teleological Time in the Hebrew Bible", in Rosen 2004, 111-26.

Brin, Gershon (2001), The Concept of Time in the Bible and the Dead Sea Scrolls (Leiden: E. J. Brill).

Brown, David (2000), "The Cuneiform Conception of Celestial Space and Time", Cambridge Archaeological Journal, 10: 103-22.

Casey, Edward (1998), The Fate of Place: A Philosophical History (Berkeley, CA: Univ. of California Press). 
Clay, Jenny (2003), Hesiod's Cosmology (Cambridge University Press).

Couprie, Dirk (2011), Heaven and Earth in Ancient Greek Cosmology (NY: Springer).

Derchain, Phillipe (1992), "Egyptian Cosmogony", "Egyptian Anthropology", in Greek and Egyptian Mythologies, Yves Bonnefoy (ed.); trans. by Wendy Doniger (Chicago, IL: Univ. of Chicago Press), 215-39.

Dunand, F. \& Zivie-Coche, C. (2004), Gods and Men in Egypt 3000 BCE- 395 CE. Trans. by David Lorton (Ithaca, NY: Cornell University Press).

Dalley, Stephanie (ed.) (2000), Myths from Mesopotamia. (revised edition) (Oxford University Press).

Edlund-Berry, Ingrid (2006), "Ritual Space and Boundaries in Etruscan Religion", in Nancy Thomson \& Erika Simon (eds.), The Religion of the Etruscans (University of Texas Press).

Eliade, Mircea (1959), Cosmos and History: The Myth of the Eternal Return, trans. by Willard Trask (NY: Harper \& Row).

Frankfort, H. A. G. (1978), Arrest and Movement: An Essay on Space and Time in the Representational Art of the Ancient Near East (NY: Hacker Arts Books).

Gantz, Timothy (1993), Early Greek Myth. 2 vols. Baltimore (MD: Johns Hopkins University Press).

Glassner, Jean-Jacques (2004), Mesopotamian Chronicles (Atlanta, GA: Society for Biblical Literature).

Horowitz, Wayne (1998), Mesopotamian Cosmic Geography (Winona Lake, IN: Eisenbrauns).

Kahn, Charles (1960), Anaximander and the Origins of Greek Cosmology (NY: Columbia University Press).

Lambert, W. G. (1975), "The Cosmology of Sumer and Babylon”, in Carmen Backer \& Michael Lowe (eds.), Ancient Cosmologies (London: Allen \& Unwin).

Leskov, Leonard (1977), The Book of Two Ways (Berkeley, CA: University of California Press).

Leick, Gwendolyn (2001), Mesopotamia: The Invention of the City (Penguin Books).

MacDonald, Paul S. (2005), "Palaeo-philosophy: Complex and Concept in Archaic Patterns of Thought", Cosmos and History, 1 (2): 222-44.

MacDonald, Paul S. (forthcoming), "Archaic ideas about knowledge in Homeric Greek, Ancient Near Eastern and Ancient Egyptian texts" in Martin Ovens (ed.), What is Comparative Philosophy? Cambridge Scholars Editions, forthcoming.

McEwen, Indra (1993), Socrates' Ancestor: An Essay on Architectural Beginnings (Cambridge, MA: MIT Press).

Malamat, Abraham (1989), Mari and the Early Israelite Experience (Oxford University Press).

Nielsen, Marjatta (1999), "The Conception of time among the Etruscans", Leidschrift, 14: 33-46.

Pinch, Geraldine (2002), Egyptian Mythology (Oxford University Press), Ch. Two, "Time Lines".

Purves, Alex C. (2004), “Topographies of Time in Hesiod”, in Rosen 2004, 147-67. 
Purves, Alex C. (2010), Space and Time in Ancient Greek Narrative (Cambridge University Press).

Rochberg, Francesca (2004), The Heavenly Writing: Divination, Horoscopy, and Astronomy in Mesopotamian Culture (Cambridge University Press).

Rochberg, Francesca (2008), "Mesopotamian Cosmology", in Companion to the Ancient Near East. Daniel Snell (ed.) (Blackwell), 316-29.

Rochberg, Francesca (2010), In the Path of the Moon: Babylonian Celestial Divination and its Legacy (Leiden: E. J. Brill).

Rosen, Ralph M. (ed.) (2004), Time and Temporality in the Ancient World (Pittsburgh, PA: Univresity of Pennsylvania Press).

Sjöberg, A. W. (2002), "In the Beginning", in Tzvi Abusch (ed.), Riches Hidden in Secret Places (Winona Lake, IN: Eisenbrauns).

Stevens, Natalie (2009), "A New Reconstruction of the Etruscan Heaven", American Journal of Archaeology, 113: 153-64.

Topoi Conference (2012), Cast in Space: Images, Gaze and Place in the Ancient World. Dominik Bonatz (Org.) (Berlin, Topoi Villa).

Trompf, G. W. (1979), The Idea of Historical Recurrence in Western Thought (Berkeley, CA: University of California Press).

Van der Meer, L. B. (1987), The Bronze Liver of Piacenza (Amsterdam: J. G. Gieben).

Vernant, Jean-Pierre (1983), Myth and Thought Among the Greeks, trans by H. Piat (London: Routledge \& Kegan Paul).

Walker, Christopher (1996), Astronomy Before the Telescope (London: British Museum Press).

Whitrow, C. J. (1988), Time in History: Views of Time from Prehistory to the Present Day (Oxford University Press).

Wyatt, Nicholas (2001), Space and Time in the Religious Life of the Near East (Sheffield, UK: Sheffield Academic). 